\title{
Macro news and stock returns in the Euro area: $A$ VAR-GARCH-in-mean analysis 2 र
}

\author{
Guglielmo Maria Caporale ${ }^{\mathrm{a}, \mathrm{b}, \mathrm{c}, *}$, Fabio Spagnolo ${ }^{\mathrm{a}}$, Nicola Spagnolo ${ }^{\mathrm{a}, \mathrm{d}}$ \\ a Department of Economics and Finance, Brunel University London, UK \\ ${ }^{\mathrm{b}}$ CESifo, Munich, Germany \\ c DIW, Berlin, Germany \\ d Centre for Applied Macroeconomic Analysis (CAMA), Canberra, Australia
}

\section{A R T I C L E I N F O}

\section{Article history:}

Received 24 July 2015

Received in revised form 11 December 2015

Accepted 18 March 2016

Available online 05 April 2016

\section{JEL Classification: \\ C32}

F36

G15

Keywords:

Macro news

Volatility spillovers

VAR-GARCH-in-mean model

\begin{abstract}
A B S T R A C T
This paper analyses the effects of newspaper coverage of macro news on stock returns in eight countries belonging to the euro area (Belgium, France, Germany, Greece, Ireland, Italy, Portugal and Spain) using daily data for the period 1994-2013. The econometric analysis is based on the estimation of a VAR-GARCH-in-mean model. The results can be summarised as follows. Positive (negative) news have significant positive (negative) effects on stock returns in all cases. Their volatility has a significant impact on both stock returns and volatility; specifically, an increase in news volatility is always associated with a decrease in stock returns. Markets are particularly responsive to negative news, and the reaction is bigger in the PIIGS countries, and during the recent crisis period. (c) 2016 The Authors. Published by Elsevier Inc. This is an open access article under the CC BY license
\end{abstract} (http://creativecommons.org/licenses/by/4.0/).

\section{Introduction}

The effects of macroeconomic news on stock prices have been analysed extensively in the more recent financial literature. The theoretical motivation comes from asset pricing models according to which factors driving macro series such as consumption and investment should also affect asset prices (e.g., Merton, 1973). In particular, according to the efficient market hypothesis, asset prices should fully reflect all available information and therefore react only to the arrival of new information in the form of "surprises" which can affect agents' expectations about future economic activity, and consequently cash flows and the discounting factor (which is a function of the risk-free interest rate and the risk premium). More specifically, two sources of news effects have been identified: scheduled macroeconomic announcements that do not correspond to agents' expectations (the announcement effect) and unscheduled announcements (the surprise effect). Most studies focus on the former, and follow the so-called "excess impact" approach

\footnotetext{
it We would like to thank the Editor and an anonimous referee for very useful comments and suggestions.

* Corresponding author at: Department of Economics and Finance, Brunel University London, UB8 3PH, UK.

E-mail address: Guglielmo-Maria.Caporale@brunel.ac.uk (G.M. Caporale).
}

(see Hanousek, Kocenda, \& Kutan, 2009 and Kocenda \& Hanousek, 2011), calculating the difference between news releases and their expected value based on surveys, and then defining positive and negative news accordingly. This strand of the literature is now extensive, and has provided plenty of evidence that news about monetary variables such as money growth and interest rates can affect stock prices (see, e.g., Chen, 1991; Cornell, 1983; Pearce \& Roley, 1983, 1985). By contrast, it is much less clear that real sector news (such as news on GDP, unemployment, retail sales and durable goods) have a significant impact on financial markets. For instance, a well-known study by Flannery and Protopapadakis (2002) concludes that there is no effect of various categories of macro news releases on stock prices.

One possible explanation is that the impact of news varies over the business cycle; for instance, McQueen and Roley (1993) are able to find an effect of real sector news during periods of expansion, and also report asymmetric effects of good news depending on the state of the economy. Similarly, Boyd, Hu, and Jagannathan (2005) find that positive news about unemployment increase stock prices during recessions but decreases them during expansions. Andersen, Bollerslev, Diebold, and Vega $(2003,2007)$ also show that the response of equities and bonds depends on the phase of the cycle; for instance, in the case of the latter bad news have stronger effects during expansions, and good news during contractions. Other economic factors might also play a role. An 
example is the more pronounced effects of macro news on the US dollar/euro (previously DEM) exchange rate in periods of high exchange rate volatility (or following a change in the direction of news) that is reported by Ehrmann and Fratzscher (2005). The relative importance of different type of news might change as well: a case in the point is the US, where shifts in monetary policy (specifically the introduction of new targets) meant that investors shifted their attention from trade balance and unemployment news to other indicators (see Bacchetta \& van Wincoop, 2013).

Another interesting issue is how heterogeneity of beliefs across market participants affects the response of financial variables to news surprises. In particular, Pericoli and Veronese (2015) use the dispersion of analysts' forecasts to proxy it and examine its impact on the response of the US dollar/euro exchange rate as well as the US and German longterm interest rates from 1999 to 2014. Their evidence suggests that surprises have a stronger effect when forecaster heterogeneity is lower, regardless of the frequency. Even more crucially, as pointed out by Birz and Lott (2013), the effects of news surprises could depend on their interpretation by agents: for instance, during a recession an increase in the growth rate could result in higher stock prices because of the improved economic prospects, but during an expansion the effect might be negative because of the expectation of higher interest rates. For this reason, Birz and Lott (2013) in their study for the US use newspaper headlines, which provide an interpretation of news releases, and find that news on GDP and unemployment affect stock returns.

As highlighted in some recent literature, the relationship between news and financial markets could be explained in terms of investor psychology. Keynes (1936) had described irrational behaviour not linked to economic fundamentals as "animal spirits". Subsequently, some theoretical models have been developed to analyse the effects of investor sentiment on stock markets in terms of informational asymmetries or other factors such as liquidity and the degree of risk aversion. An example of the former type of model is offered by De Long, Shleifer, Summers, and Waldmann (1990), who distinguish between two categories of traders, namely rational arbitrageurs updating their Bayesian beliefs on the basis of economic fundamentals, and noise traders with random beliefs. In such a framework, given the assumption of risk aversion and/or constraints faced by investors, low sentiment has a (temporary) negative effect on prices but increases volume, as noise traders react to negative belief shocks by selling shares to rational arbitrageurs. Campbell, Grossman, and Wang (1993) explain the same price and volume effects in terms of changes in risk aversion. In other studies such as Coval and Shumway (2001) and Antweiler and Frank (2004) investor sentiment is instead related to trading costs, and the perception of a more negative outlook results in lower trading volumes.

The extent to which low investor sentiment, leading to downward price movements, can be linked to media "pessimism" (corresponding to "bad news" in the present study) is the issue analysed in an important study by Tetlock (2007). He constructs a media pessimism variable using content from the Wall Street Journal, and then examines its impact on market returns in the US by estimating a VAR model. As he points out, such a variable could be interpreted as a proxy for either investor sentiment or risk aversion (which cannot be disentangled empirically), as in the papers by De Long et al. (1990) and Campbell et al. (1993) (noise and liquidity trader theories respectively), in which case pessimism should increase volume, or alternatively as a proxy for trading costs, when pessimism should decrease volume. A further important question raised by Tetlock (2007) is whether pessimism forecasts future or reflects past sentiment. In the former case, one should observe low returns in the short run followed by mean reversion over a longer time span; in the latter, pessimism should be a consequence of past low returns and higher future returns should be forecast. Also, pessimism could be due either to negative information about asset prices not already incorporated in them, or negative information about dividends already reflected in them. The empirical evidence reported by Tetlock (2007) suggests that pessimism has a negative effect on prices in the short run, with mean reversion then occurring, and also results in higher trading volume; the implication is that models of noise and liquidity traders are the ones capable of accounting for the effects of low investor sentiment on financial markets. Another interesting finding is that the price effects are more pronounced for small stocks: it would appear therefore that news affect the behaviour of individual investors whose portfolio includes a relatively high percentage of such stocks. A follow-up study by Tetlock, Saar-Tsechansky, and Macskassy (2008) provides additional evidence that negative news can predict market returns.

Fang and Peress (2009) use a wider dataset including more US daily newspapers and a cross-section of countries and find higher returns for stocks with no media coverage compared to those with high coverage (even controlling for risk factors), especially in the case of small stocks with high ownership by individual investors. They consider two possible explanations for such an arbitrage opportunity, namely (i) the "impediments to trade" (or "illiquidity") hypothesis, i.e. the existence of constraints preventing investors from exploiting this opportunity for abnormal profits, or (ii) the "investor recognition" hypothesis (see Merton, 1987), the idea being that media coverage can increase the degree of recognition and therefore the corresponding returns on stocks only recognised by a few agents and consequently not sufficiently diversified. Their conclusion is that the second explanation applies, and hence media coverage affects asset prices by disseminating information broadly, even if it does not represent news. ${ }^{1}$

Following Birz and Lott (2013), the present paper also focuses on the effects of newspaper coverage of macro news on stock prices. However, it has a number of distinctive features. First, unlike the study of Birz and Lott (2013), where only the effects of macro news on stock returns are considered, it adopts an econometric framework that sheds light on both mean and volatility spillovers between these two variables. Specifically, it estimates a VAR-GARCH-in-mean model with a BEKK representation (see below for details), where the GARCH-in-mean parameter captures the impact of news volatility on stock returns, which is another novel contribution to the literature. Second, it provides evidence on linkages between macro news and financial markets in the euro area, for which no similar studies exist. The analysis reveals some interesting differences between the core and peripheral (PIIGS) countries in the way financial markets respond to macro news. Third, it examines whether the recent global financial crisis has had an impact on these linkages, in particular whether European financial markets have become more sensitive to macro news. Fourth, it controls for monetary policy and financial globalisation.

Of course, other GARCH specifications have been estimated in this area of the literature. An example is the paper by Belgacem, Creti, Guesmi, and Lahiani (2015) that uses an augmented DCC-GARCH model (see Engle, 2002). The analysis is particularly interesting in that it distinguishes between the direct and indirect effects of US macro news on US stock markets and oil prices. Further, it shows that there are bidirectional volatility spillovers between stock and oil markets, and provides evidence on what type of news have the most pronounced effects. Several other competing models could also be considered, such as CCC-GARCH, and different types of BEKK representations (diagonal, scalar and full) as in the study by

\footnotetext{
${ }^{1}$ Evidence on the direction of causality, running from media to stock market variables, is provided by both Engelberg and Parsons (2011) and Peress (2011); the former compare the behaviour of investors with access to different media coverage of the same event, whilst the latter examines the exogenous impact of news blackouts resulting from newspaper strikes. All the studies mentioned so far, however, only analyse mean spillovers.
} 
Arouri et al. (2015 - though in a different context, namely to analyse the relationship between world gold prices and stock returns in China). Our choice of the VAR-GARCH-in-mean model with a BEKK representation as detailed below was motivated by its properties: this type of specification enables the researcher to test for causality in variance, causality in mean and GARCH in mean effects (along with the conditional correlations) within the same framework. Given the relatively high number of model parameters (in particular, considering the fact that in our case the inclusion of dummy variables to analyse the effects of the global crises doubles the number of cross parameters to be estimated), the chosen specification appears to be the most appropriate to model the time-varying dynamic linkages between the variables of interest. In contrast to the studies just mentioned, ours deals with a relatively small number of variables (three) but a rather high number of parameters. Our choice was essentially motivated by this set of constraints.

The layout of the paper is as follows. Section 2 outlines the econometric modelling approach. Section 3 describes the data and presents the empirical findings. Section 4 summarises the main findings and offers some concluding remarks.

\section{The model}

We represent the first and second moments of stock market returns and news using a VAR-GARCH $(1,1)$-in-mean process. ${ }^{2}$ In its most general specification the model takes the following form:

$\mathrm{x}_{t}=\alpha+\beta \mathrm{x}_{t-1}+\theta \mathrm{h}_{t-1}+\delta \mathrm{f}_{t-1}+\mathrm{u}_{t}$

where $\mathrm{x}_{t}=\left(\right.$ StockRet $_{t}$, PositiveNews ${ }_{t}$, NegativeNews $\left._{t}\right)$ and $\mathrm{x}_{t-1}$ is a corresponding vector of lagged variables. We control for monetary policy shocks by including in the mean equation the domestic 90day Treasury Bill rate. Furthermore, exogenous shocks measured by US stock market returns, $\mathrm{f}_{t-1}=\left(\right.$ TBill Interest $_{t-1}$, US ret $\left.t_{t-1}\right)$, are used as a proxy for market globalisation. ${ }^{3}$ The residual vector $\mathrm{u}_{t}=\left(e_{1, t}, e_{2, t}, e_{3, t}\right)$ is trivariate and normally distributed $\mathrm{u}_{t} \mid I_{t-}$ $1 \sim\left(0, H_{t}\right)$ with its corresponding conditional variance covariance matrix given by:

$H_{t}=\left[\begin{array}{lll}h_{11 t} & h_{12 t} & h_{13 t} \\ h_{12 t} & h_{22 t} & h_{23 t} \\ h_{13 t} & h_{23 t} & h_{33 t}\end{array}\right]$

The parameters vector of the mean return Eq. (1) is defined by the constant $\alpha=\left(\alpha_{1}, \alpha_{2}, \alpha_{3}\right)$, the autoregressive term, $\beta=\left(\beta_{11}\right.$, $\left.\beta_{12}+\beta_{12}{ }^{*}, \beta_{13}+\beta_{13}{ }^{*}\left|\beta_{21}, \beta_{22}, 0\right| \beta_{31}, 0, \beta_{33}\right)$, which allows for mean return effects from positive $\left(\beta_{12}\right)$ and negative $\left(\beta_{13}\right)$ news, and the GARCH-in-mean parameter $\theta=\left(\theta_{12}+\theta_{12}{ }^{*}, \theta_{13}+\theta_{13}{ }^{*}|0,0| 0,0\right)$, which allows for mean return effects from positive $\left(\theta_{12}\right)$ and negative news volatility $\left(\theta_{13}\right)$. The parameters $\beta_{21}$ and $\beta_{31}$ capture the potential reverse causation effect in the case of newspaper news

\footnotetext{
2 The model is based on the GARCH(1,1)-BEKK representation proposed by Engle and Kroner (1995). As previously mentioned, this model was preferred to a set of competing models, such as the DCC-GARCH family models, given the relatively small number of variables and rather high number of parameters to be estimated.

${ }^{3}$ Birz and Lott (2011) also control for news surprises, computed in the standard way; however, they find that these are not statistically significant. This is not surprising, considering the fact that typically news are released on a very small percentage of trading days (e.g., in the case of the sample for the CIVETS stock markets examined by Wallenius, Fedorova, \& Collan, 2013, no release took place on $70.5 \%$ trading days and only $4.7 \%$ trading days had multiple releases), in contrast to newspaper coverage of macro news, which is daily and can be modelled appropriately using a GARCH framework. For this reason, we do not include news surprises in the model specification. Concerning day-of-the week and business cycle effects, also considered by Birz and Lott (2011), we found that a dummy for the day-of-the-week was not significant (and therefore did not include it in the chosen specification), and similarly that there is no evidence of differences in the responses of stock returns depending on the state of the economy (these additional results are not reported in the paper).
}

Table 1

Descriptive Statistics.

\begin{tabular}{|c|c|c|c|c|c|c|c|c|}
\hline & \multicolumn{4}{|c|}{ Pre-September 2008} & \multicolumn{4}{|c|}{ Post-September 2008} \\
\hline & Mean & Std. dev & Min & Max & Mean & Std. dev & Min & Max \\
\hline \multicolumn{9}{|c|}{ Positive news } \\
\hline Belgium & 0.12 & 0.64 & 0 & 14 & 0.31 & 2.98 & 0 & 98 \\
\hline France & 0.69 & 1.92 & 0 & 27 & 1.94 & 4.26 & 0 & 104 \\
\hline Germany & 3.28 & 3.99 & 0 & 25 & 6.43 & 9.67 & 0 & 106 \\
\hline Greece & 0.06 & 0.04 & 0 & 9 & 1.32 & 6.26 & 0 & 91 \\
\hline Ireland & 0.04 & 0.09 & 0 & 8 & 0.48 & 2.11 & 0 & 57 \\
\hline Italy & 0.42 & 0.29 & 0 & 15 & 0.85 & 4.77 & 0 & 86 \\
\hline Portugal & 0.11 & 0.06 & 0 & 10 & 0.57 & 3.47 & 0 & 74 \\
\hline Spain & 0.20 & 0.18 & 0 & 12 & 0.88 & 5.05 & 0 & 77 \\
\hline \multicolumn{9}{|c|}{ Negative news } \\
\hline Belgium & 0.07 & 0.50 & 0 & 8 & 0.49 & 4.23 & 0 & 102 \\
\hline France & 0.25 & 0.89 & 0 & 11 & 1.47 & 5.66 & 0 & 106 \\
\hline Germany & 0.86 & 2.14 & 0 & 18 & 2.47 & 4.61 & 0 & 99 \\
\hline Greece & 0.05 & 0.45 & 0 & 2 & 1.81 & 4.77 & 0 & 116 \\
\hline Ireland & 0.07 & 0.09 & 0 & 3 & 0.81 & 2.11 & 0 & 95 \\
\hline Italy & 0.35 & 1.18 & 0 & 2 & 1.92 & 3.73 & 0 & 108 \\
\hline Portugal & 0.07 & 0.52 & 0 & 2 & 0.81 & 3.62 & 0 & 77 \\
\hline Spain & 0.12 & 0.89 & 0 & 6 & 1.29 & 4.01 & 0 & 100 \\
\hline \multicolumn{9}{|c|}{ Stock returns } \\
\hline Belgium & 0.014 & 0.011 & & & 0.062 & 0.012 & & \\
\hline France & 0.023 & 0.012 & & & 0.029 & 0.014 & & \\
\hline Germany & 0.024 & 0.012 & & & 0.042 & 0.017 & & \\
\hline Greece & 0.036 & 0.015 & & & -0.035 & 0.021 & & \\
\hline Ireland & 0.023 & 0.013 & & & 0.051 & 0.018 & & \\
\hline Italy & 0.021 & 0.012 & & & 0.06 & 0.016 & & \\
\hline Portugal & 0.018 & 0.009 & & & 0.007 & 0.013 & & \\
\hline Spain & 0.035 & 0.011 & & & 0.012 & 0.017 & & \\
\hline
\end{tabular}

Note: Stock market returns are the daily percentage changes in the closing values of the national stock market indices. News counts refer to domestic and international (within the Euro area) media coverage. The number of positive (negative) newspaper headlines index is defined as follows: positive (negative) news index $=\ln [e+$ domestic positive (negative) news + international positive (negative) news]. Min and max values refer to the raw story counts. The sample size covers the period 03/1/1994-12/5/2013, for a total of 5058 observations.

(Birz and Lott, 2013) as journalists might be influenced by the stock market closing prices when writing articles. Furthermore, $\delta=$ $\left(\delta_{12}, \delta_{13}|0,0| 0,0\right)$ is the vector of control parameters, monetary policy and exogenous shocks respectively appearing in the first equation only. ${ }^{4}$ In order to account for the possible effects of the recent financial crisis, we include a dummy variable (denoted by *) with a switch on 15 September 2008, i.e. on the day of the collapse of Lehman Brothers. Therefore, the second moment will take the following form ${ }^{5}$ :

$$
\begin{aligned}
H_{t}= & C_{0}^{\prime} C_{0}+A_{11}^{\prime}\left[\begin{array}{lll}
e_{1, t-1}^{2} & e_{2, t-1} e_{1, t-1} & e_{3, t-1} e_{1, t-1} \\
e_{1, t-1} e_{2, t-1} & e_{2, t-1}^{2} & e_{3, t-1} e_{2, t-1} \\
e_{1, t-1} e_{3, t-1} & e_{2, t-1} e_{3, t-1} & e_{3, t-1}^{2}
\end{array}\right] A_{11} \\
& +G_{11}^{\prime} H_{t-1} G_{11}
\end{aligned}
$$

where

$A_{11}=\left[\begin{array}{lll}a_{11} & 0 & 0 \\ a_{21}+a_{21}^{*} & a_{22} & 0 \\ a_{31}+a_{31}^{*} & 0 & a_{33}\end{array}\right] ; G_{11}=\left[\begin{array}{lll}g_{11} & 0 & 0 \\ g_{21}+g_{21}^{*} & g_{22} & 0 \\ g_{31}+g_{31}^{*} & & g_{33}\end{array}\right]$

Eq. (3) models the dynamic process of $H_{t}$ as a linear function of its own past values $H_{t-1}$ and past values of the squared innovations

\footnotetext{
${ }^{4}$ Please note that the control variables are treated as exogenous in order to obtain a system of equations of manageable dimensions. Both variables are lagged in order to control for any potential endogeneity and to capture the often non-contemporaneous effects of monetary and global market variables.

5 The parameters $\left(a_{21}\right)$ and $\left(a_{31}\right)$ in Eq. (3) measure the causality effect of positive and negative news volatility respectively, whereas $\left(a_{21}+a_{21}^{*}\right)$ and $\left(a_{31}+a_{31}^{*}\right)$ the possible effect of the 2008 financial crisis.
} 
Belgium
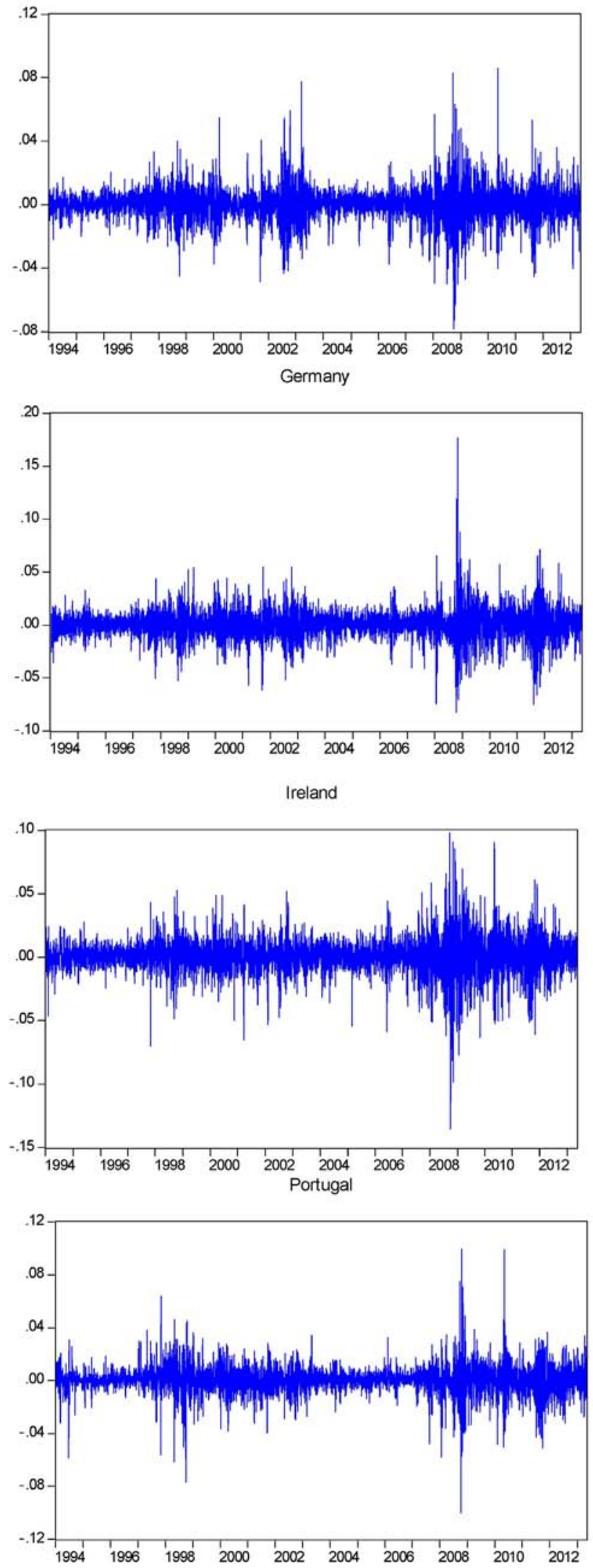

France
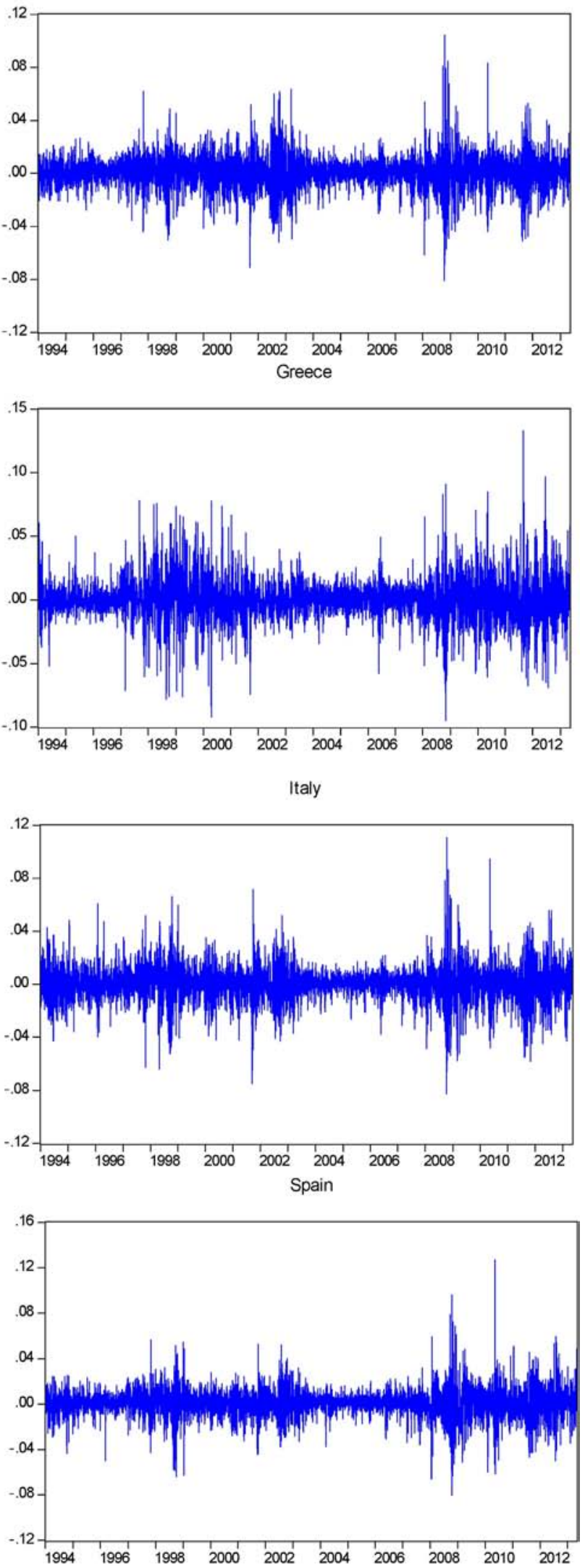

Fig. 1. Stock market returns.

$\left(e_{1, t-1}^{2}, e_{2, t-1}^{2}, e_{3, t-1}^{2}\right)$. The parameters of ( 3$)$ are given by $C_{0}$, which is restricted to be upper triangular, and the two matrices $A_{11}$ and $G_{11}$. Each of these two has four zero restrictions since we are focusing on volatility spillovers (causality-in-variance) from positive news volatility before $\left(a_{21}\right)$ and after the crisis $\left(a_{21}+a_{21}{ }^{*}\right)$, as well as from negative news volatility before $\left(a_{31}\right)$ and after the crisis 
Table 2

Estimated VAR-GARCH(1,1)-in-mean model.

\begin{tabular}{|c|c|c|c|c|}
\hline & \multicolumn{2}{|l|}{ Belgium } & \multicolumn{2}{|l|}{ France } \\
\hline & coefficient & S.E. & coefficient & S.E. \\
\hline \multicolumn{5}{|c|}{ Conditional Mean Equation } \\
\hline$\alpha_{1}$ & 0.0019 & $(0.0001)$ & 0.0011 & $(0.0004)$ \\
\hline$\alpha_{2}$ & 0.0168 & $(0.0103)$ & 0.0351 & $(0.0081)$ \\
\hline$\alpha_{3}$ & 0.1032 & $(0.0169)$ & 0.1443 & $(0.0271)$ \\
\hline$\beta_{11}$ & -0.1726 & $(0.0399)$ & -0.0279 & $(0.0137)$ \\
\hline$\beta_{12}$ & 0.0009 & $(0.0002)$ & 0.0032 & $(0.0013)$ \\
\hline$\beta_{12}^{*}$ & 0.0012 & $(0.0003)$ & 0.0006 & $(0.002)$ \\
\hline$\beta_{13}$ & -0.0010 & $(0.0004)$ & -0.0003 & $(0.0001)$ \\
\hline$\beta_{13}^{*}$ & -0.0001 & $(0.0001)$ & -0.0003 & $(0.0001)$ \\
\hline$\theta_{12}$ & -0.0029 & $(0.0011)$ & -0.0007 & $(0.0003)$ \\
\hline$\theta_{12}^{*}$ & -0.0048 & $(0.0021)$ & -0.0033 & $(0.0015)$ \\
\hline$\theta_{13}$ & -0.0111 & $(0.0046)$ & -0.0042 & $(0.0019)$ \\
\hline$\theta_{13}^{*}$ & -0.0015 & $(0.0005)$ & -0.0012 & $(0.0005)$ \\
\hline$\gamma_{11}$ & 0.3281 & $(0.0366)$ & 0.0254 & $(0.0137)$ \\
\hline$\gamma_{12}$ & -0.0482 & $(0.0191)$ & -0.0033 & $(0.0016)$ \\
\hline \multicolumn{5}{|c|}{ Conditional variance equation } \\
\hline$c_{11}$ & 0.0001 & $(0.0001)$ & 0.0001 & $(0.0001)$ \\
\hline$c_{22}$ & 0.0775 & $(0.0162)$ & 0.0233 & $(0.0107)$ \\
\hline$c_{33}$ & 0.5505 & $(0.0574)$ & 0.0257 & $(0.0175)$ \\
\hline$g_{11}$ & 0.9474 & $(0.0374)$ & 0.9337 & $(0.0161)$ \\
\hline$g_{21}$ & 0.0155 & $(0.0062)$ & -0.1571 & $(0.0614)$ \\
\hline$g_{21}^{*}$ & 0.0084 & $(0.0037)$ & -0.0302 & $(0.0112)$ \\
\hline$g_{22}$ & 0.9631 & $(0.0209)$ & 0.9852 & $(0.0326)$ \\
\hline$g_{31}$ & 0.0941 & $(0.0423)$ & -0.1578 & $(0.0543)$ \\
\hline$g_{31}^{*}$ & -0.6748 & $(0.2251)$ & -0.1901 & $(0.0871)$ \\
\hline$g_{33}$ & 0.9846 & $(0.1377)$ & 0.9895 & $(0.0018)$ \\
\hline$a_{11}$ & 0.3076 & $(0.0763)$ & 0.2884 & $(0.0475)$ \\
\hline$a_{21}$ & -0.0516 & $(0.0231)$ & 0.3701 & $(0.1541)$ \\
\hline$a_{21}^{*}$ & -0.0026 & $(0.0011)$ & 0.1834 & $(0.0752)$ \\
\hline$a_{22}$ & 0.2376 & $(0.0113)$ & 0.1757 & $(0.0257)$ \\
\hline$a_{31}$ & -0.2140 & $(0.1012)$ & 0.4075 & $(0.2017)$ \\
\hline$a_{31}^{*}$ & -0.3028 & $(0.1291)$ & 0.7049 & $(0.3435)$ \\
\hline$a_{33}$ & 0.1395 & $(0.0846)$ & 0.1568 & $(0.0167)$ \\
\hline LogLik & 26499.96 & & 18467.53 & \\
\hline$L B_{\text {Stock, (10) }}$ & 7.1261 & & 8.4563 & \\
\hline$L B_{\text {Stock,(10) }}^{2}$ & 9.2298 & & 7.1351 & \\
\hline
\end{tabular}

Note: Standard errors (S.E.) are calculated using the quasi-maximum likelihood method of Bollerslev and Wooldridge (1992), which is robust to the distribution of the underlying residuals. Parameters not statistically significant at the $10 \%$ level are not reported. LB $_{S t o c k(10)}$ and $\mathrm{LB}_{S \operatorname{st}(10)}^{2}$ are the Ljung-Box test (1978) of significance of autocorrelations of ten lags in the standardised and standardised squared residuals respectively. The parameters $\beta_{12}$ and $\beta_{13}$ measure the causality effect of positive and negative news on stock returns respectively, $a_{21}$ and $a_{31}$ measure the causality in variance effect of positive and negative news respectively whereas $\theta_{12}$ and $\theta_{13}$ capture the effect of positive and negative news volatility on stock market returns. The effect of the 2008 financial crises on returns is measured by $\left(\beta_{12}+\beta_{12}^{*}\right)$ and $\left(\beta_{13}+\beta_{13}^{*}\right)$ whereas $\left(a_{21}+a_{21}^{*}\right)$ and $\left(a_{31}+a_{31}^{*}\right)$ capture the effect on stock return volatilities. The covariance stationarity condition is satisfied by all the estimated models, all the eigenvalues of $A_{11} \otimes A_{11}+G_{11} \otimes G_{11}$ being less than one in modulus. Note that in the conditional variance equation the sign of the parameters cannot be determined.

$\left(a_{31}+a_{31}{ }^{*}\right)$, to stock returns volatility only and not viceversa. The BEKK representation guarantees by construction that the covariance matrix in the system is positive definite. Furthermore, the conditional correlations between equity markets and positive and negative news respectively will be given by:

$\rho_{12, t}=h_{12, t} / \sqrt{h_{11, t}} \sqrt{h_{22, t}}$ and $\rho_{13, t}=h_{13, t} / \sqrt{h_{11, t}} \sqrt{h_{33, t}}$

Given a sample of $T$ observations, a vector of unknown parameters $\theta$ and a $3 \times 1$ vector of variables $x_{t}$, the conditional density function for model (1) is:

$f\left(\mathrm{x}_{t} \mid I_{t-1} ; \theta\right)=(2 \pi)^{-1}\left|H_{t}\right|^{-1 / 2} \exp \left(-\frac{u_{t}^{\prime}\left(H_{t}^{-1}\right) u_{t}}{2}\right)$
The log-likelihood function is:

$L=\sum_{t=1}^{T} \log f\left(\mathrm{x}_{t} \mid I_{t-1} ; \theta\right)$

where $\theta$ is the vector of unknown parameters. The standard errors are calculated using the quasi-maximum likelihood methods of Bollerslev and Wooldridge (1992), which is robust to the distribution of the underlying residuals.

\section{Empirical analysis}

\subsection{Data}

We use daily data (from Bloomberg) for eight countries (Belgium, France, Germany, Greece, Ireland, Italy, Portugal and Spain) belonging to the Euro area over the period 03/1/1994-12/5/2013, for a total of 5058 observations. Furthermore, as already mentioned, we control for monetary policy and stock market globalisation using domestic interest rates (90-day Treasury Bill rate) and a proxy for the global stock market index (US stock market index). We define daily returns as logarithmic differences of stock indices.

We consider news coverage of four macro economic data series, i.e. GDP, unemployment, retail sales and durable goods (Birz and Lott, 2013). The data for the news index are collected from Bloomberg where news coverage is proxied by story headline counts. News headlines were selected using an extensive string search, containing words

Table 3

Estimated VAR-GARCH(1,1)-in-mean model.

\begin{tabular}{|c|c|c|c|c|}
\hline & \multicolumn{2}{|l|}{ Germany } & \multicolumn{2}{|l|}{ Greece } \\
\hline & coefficient & S.E. & coefficient & S.E. \\
\hline \multicolumn{5}{|c|}{ Conditional mean equation } \\
\hline$\alpha_{1}$ & 0.0033 & $(0.0011)$ & 0.0006 & $(0.0005)$ \\
\hline$\alpha_{2}$ & 0.3058 & $(0.0369)$ & 0.0007 & $(0.0014)$ \\
\hline$\alpha_{3}$ & 0.1568 & $(0.0294)$ & 0.0188 & $(0.0095)$ \\
\hline$\beta_{11}$ & -0.0405 & $(0.0182)$ & 0.0758 & $(0.0243)$ \\
\hline$\beta_{12}$ & 0.0001 & $(0.0001)$ & 0.0006 & $(0.0002)$ \\
\hline$\beta_{12}^{*}$ & 0.0016 & $(0.0002)$ & 0.0112 & $(0.0046)$ \\
\hline$\beta_{13}$ & -0.0008 & $(0.0003)$ & -0.0007 & $(0.0031)$ \\
\hline$\beta_{13}^{*}$ & -0.0009 & $(0.0004)$ & -0.0054 & $(0.0026)$ \\
\hline$\theta_{12}$ & -0.0062 & $(0.0029)$ & -0.3547 & $(0.1274)$ \\
\hline$\theta_{12}^{*}$ & -0.0023 & $(0.0011)$ & 0.3312 & $(0.1563)$ \\
\hline$\theta_{13}$ & -0.0026 & $(0.0009)$ & -0.0045 & $(0.0012)$ \\
\hline$\theta_{13}^{*}$ & -0.0112 & $(0.0462)$ & -0.5332 & $(0.2219)$ \\
\hline$\gamma_{11}$ & 0.3365 & $(0.0211)$ & 0.1169 & $(0.0312)$ \\
\hline$\gamma_{12}$ & -0.0008 & $(0.0002)$ & -0.0003 & $(0.0001)$ \\
\hline \multicolumn{5}{|c|}{ Conditional variance equation } \\
\hline$c_{11}$ & 0.0001 & $(0.0001)$ & 0.0017 & $(0.0003)$ \\
\hline$c_{22}$ & 0.0508 & $(0.0136)$ & 0.0044 & $(0.0017)$ \\
\hline$c_{33}$ & 0.0274 & $(0.0072)$ & 0.0416 & $(0.0178)$ \\
\hline$g_{11}$ & 0.9673 & $(0.0066)$ & 0.9363 & $(0.0009)$ \\
\hline$g_{21}$ & -0.1319 & $(0.0543)$ & 0.0097 & $(0.0043)$ \\
\hline$g_{21}^{*}$ & 0.1543 & $(0.0645)$ & 0.2005 & $(0.0962)$ \\
\hline$g_{22}$ & 0.9731 & $(0.0041)$ & 0.9045 & $(0.0021)$ \\
\hline$g_{31}$ & 0.0998 & $(0.0453)$ & -0.1350 & $(0.0034)$ \\
\hline$g_{31}^{*}$ & -0.3301 & $(0.1231)$ & -0.2130 & $(0.0561)$ \\
\hline$g_{33}$ & 0.9776 & $(0.0083)$ & 0.9809 & $(0.0021)$ \\
\hline$a_{11}$ & 0.2525 & $(0.0269)$ & 0.3503 & $(0.0101)$ \\
\hline$a_{21}$ & -0.2509 & $(0.0126)$ & -0.0732 & $(0.0321)$ \\
\hline$a_{21}^{*}$ & 1.1545 & $(0.4971)$ & -0.6615 & $(0.2231)$ \\
\hline$a_{22}$ & 0.1655 & $(0.0194)$ & 0.4485 & $(0.0764)$ \\
\hline$a_{31}$ & 0.2712 & $(0.0087)$ & -0.0873 & $(0.0354)$ \\
\hline$a_{31}^{*}$ & 0.6585 & $(0.2291)$ & -0.8619 & $(0.2243)$ \\
\hline$a_{33}$ & 0.2251 & $(0.0464)$ & 0.1604 & $(0.0459)$ \\
\hline LogLik & 12734.36 & & 31115.92 & \\
\hline$L B_{\text {Stock, (10) }}$ & 4.3456 & & 10.564 & \\
\hline$L B_{\text {Stock, }(10)}^{2}$ & 7.1291 & & 10.452 & \\
\hline
\end{tabular}

Note: See the notes to Table 2. 
Table 4

Estimated VAR-GARCH(1,1)-in-mean model.

\begin{tabular}{|c|c|c|c|c|}
\hline & \multicolumn{2}{|l|}{ Ireland } & \multicolumn{2}{|l|}{ Italy } \\
\hline & coefficient & S.E. & coefficient & S.E. \\
\hline \multicolumn{5}{|c|}{ Conditional mean equation } \\
\hline$\alpha_{1}$ & 0.0048 & $(0.0007)$ & 0.0021 & $(0.0002)$ \\
\hline$\alpha_{2}$ & 0.0041 & $(0.0017)$ & 0.0048 & $(0.0046)$ \\
\hline$\alpha_{3}$ & 0.1468 & $(0.0126)$ & 0.1357 & $(0.0327)$ \\
\hline$\beta_{11}$ & 0.1356 & $(0.0524)$ & 0.1124 & $(0.0273)$ \\
\hline$\beta_{12}$ & 0.0072 & $(0.0038)$ & 0.0011 & $(0.0004)$ \\
\hline$\beta_{12}^{*}$ & 0.0104 & $(0.0051)$ & 0.0010 & $(0.0003)$ \\
\hline$\beta_{13}$ & -0.0134 & $(0.0049)$ & -0.0015 & $(0.0005)$ \\
\hline$\beta_{13}^{*}$ & -0.0129 & $(0.0023)$ & -0.0049 & $(0.0016)$ \\
\hline$\theta_{12}$ & -0.0036 & $(0.0015)$ & -0.0011 & $(0.0003)$ \\
\hline$\theta_{12}^{*}$ & 0.0024 & $(0.0009)$ & 0.0006 & $(0.0001)$ \\
\hline$\theta_{13}$ & -0.0236 & $(0.0098)$ & -0.0013 & $(0.0004)$ \\
\hline$\theta_{13}^{*}$ & -0.0224 & $(0.0083)$ & -0.0008 & $(0.0002)$ \\
\hline$\gamma_{11}$ & 0.4706 & $(0.0272)$ & 0.1289 & $(0.0364)$ \\
\hline$\gamma_{12}$ & -0.0051 & $(0.0001)$ & -0.0007 & $(0.0003)$ \\
\hline \multicolumn{5}{|c|}{ Conditional variance equation } \\
\hline$c_{11}$ & 0.0001 & $(0.0001)$ & 0.0001 & $(0.0001)$ \\
\hline$c_{22}$ & -0.0005 & $(0.0002)$ & 0.0109 & $(0.0053)$ \\
\hline$c_{33}$ & 0.0087 & $(0.0012)$ & -0.3449 & $(0.0852)$ \\
\hline$g_{11}$ & 0.9924 & $(0.0023)$ & 0.9438 & $(0.0096)$ \\
\hline$g_{21}$ & -0.0077 & $(0.0022)$ & 0.0826 & $(0.0342)$ \\
\hline$g_{21}^{*}$ & 0.0465 & $(0.0196)$ & -0.3596 & $(0.1293)$ \\
\hline$g_{22}$ & 0.6732 & $(0.0131)$ & 0.9757 & $(0.0033)$ \\
\hline$g_{31}$ & 0.0332 & $(0.0111)$ & 0.0889 & $(0.0342)$ \\
\hline$g_{31}^{*}$ & 0.1474 & $(0.0653)$ & 0.2789 & $(0.1125)$ \\
\hline$g_{33}$ & -0.9428 & $(0.0247)$ & 0.9823 & $(0.0271)$ \\
\hline$a_{11}$ & 0.1198 & $(0.0151)$ & 0.3657 & $(0.0245)$ \\
\hline$a_{21}$ & 0.0019 & $(0.0008)$ & -0.0892 & $(0.0056)$ \\
\hline$a_{21}^{*}$ & -0.4845 & $(0.1896)$ & 0.9796 & $(0.4431)$ \\
\hline$a_{22}$ & 0.1973 & $(0.0872)$ & 0.2095 & $(0.0284)$ \\
\hline$a_{31}$ & -0.4841 & $(0.2196)$ & -0.1216 & $(0.0542)$ \\
\hline$a_{31}^{*}$ & -1.6122 & $(0.5543)$ & -0.9487 & $(0.3494)$ \\
\hline$a_{33}$ & 0.0955 & $(0.1185)$ & 0.1441 & $(0.0251)$ \\
\hline LogLik & 32471.62 & & 24773.97 & \\
\hline$L B_{\text {Stock, }(10)}$ & 12.453 & & 11.329 & \\
\hline$L B_{\text {Stock, (10) }}^{2}$ & 9.775 & & 10.764 & \\
\hline
\end{tabular}

Note: see the notes to Table 2 .

indicating articles dealing with macro variables. Specifically, we searched for and discriminated between articles with a positive or negative connotations towards GDP, unemployment, retail sales and durable goods. The average number of stories about unemployment and GDP is very similar; these account for the majority of news articles, whereas there is less coverage of retail sales and durable goods releases. The index we use does not distinguish between different types of macro news, since the focus of this study is to analyse the effects of positive and negative macro news respectively as reported and interpreted by the media. ${ }^{6}$ The daily positive (negative) news index is defined as follows:

positive(negative)news index

$=\ln [\mathrm{e}+$ domestic positive (negative) news

+ international positive (negative) news]

We address the issue of national newspaper stories about the status of the economy potentially being politically biased (Birz and Lott, 2013 ) by using both domestic and international (within the Euro area) news. ${ }^{7}$

The descriptive statistics, presented in Table 1, show that on average the number of positive news releases is bigger than that

\footnotetext{
${ }^{6}$ Neutral and mixed news, which have been found not to be significant in previous studies, have not been considered given the aim of this paper.

${ }^{7}$ Please note that, following Birz and Lott (2013), we also consider the positive (negative) news index as a percentage of the total number of news. The results are available on request from the authors and are qualitatively similar.
}

Table 5

Estimated VAR-GARCH(1,1)-in-mean model.

\begin{tabular}{|c|c|c|c|c|}
\hline & \multicolumn{2}{|l|}{ Portugal } & \multicolumn{2}{|l|}{ Spain } \\
\hline & coefficient & S.E. & coefficient & S.E. \\
\hline \multicolumn{5}{|c|}{ Conditional mean equation } \\
\hline$\alpha_{1}$ & -0.0011 & $(0.0004)$ & 0.0019 & $(0.0002)$ \\
\hline$\alpha_{2}$ & 0.0044 & $(0.0022)$ & 0.0098 & $(0.0016)$ \\
\hline$\alpha_{3}$ & 0.0007 & $(0.0003)$ & 0.1346 & $(0.0391)$ \\
\hline$\beta_{11}$ & 0.0226 & $(0.0098)$ & -0.0317 & $(0.0060)$ \\
\hline$\beta_{12}$ & 0.0071 & $(0.0034)$ & 0.0006 & $(0.0002)$ \\
\hline$\beta_{12}^{*}$ & 0.0064 & $(0.0026)$ & -0.0003 & $(0.0001)$ \\
\hline$\beta_{13}$ & -0.0242 & $(0.0111)$ & -0.0041 & $(0.0017)$ \\
\hline$\beta_{13}^{*}$ & -0.0228 & $(0.0112)$ & -0.0026 & $(0.0008)$ \\
\hline$\theta_{12}$ & -0.0333 & $(0.0151)$ & -0.0168 & $(0.0057)$ \\
\hline$\theta_{12}^{*}$ & 0.0231 & $(0.0113)$ & 0.0134 & $(0.0065)$ \\
\hline$\theta_{13}$ & -0.0453 & $(0.0221)$ & -0.0169 & $(0.0049)$ \\
\hline$\theta_{13}^{*}$ & -0.0435 & $(0.0187$ & -0.0263 & $(0.0112)$ \\
\hline$\gamma_{11}$ & 0.1136 & $(0.0045)$ & 0.2854 & $(0.0532)$ \\
\hline$\gamma_{12}$ & -0.0001 & $(0.0001)$ & -0.0004 & $(0.0001)$ \\
\hline \multicolumn{5}{|c|}{ Conditional variance equation } \\
\hline$c_{11}$ & 0.0001 & $(0.0001)$ & 0.0001 & $(0.0001)$ \\
\hline$c_{22}$ & 0.0001 & $(0.0001)$ & -0.0036 & $(0.0025)$ \\
\hline$c_{33}$ & 0.0012 & $(0.0004)$ & 0.0556 & $(0.0189)$ \\
\hline$g_{11}$ & 0.7149 & $(0.2349)$ & 0.8954 & $(0.0183)$ \\
\hline$g_{21}$ & -0.0541 & $(0.0224)$ & -0.0891 & $(0.0342)$ \\
\hline$g_{21}^{*}$ & -0.1808 & $(0.0874)$ & -0.4929 & $(0.2231)$ \\
\hline$g_{22}$ & 0.9783 & $(0.0065)$ & 0.9816 & $(0.0045)$ \\
\hline$g_{31}$ & 0.0671 & $(0.0187)$ & -0.0941 & $(0.0439)$ \\
\hline$g_{31}^{*}$ & -0.2214 & $(0.1054)$ & -0.6119 & $(0.2135)$ \\
\hline$g_{33}$ & 0.9941 & $(0.0078)$ & 0.9165 & $(0.1706)$ \\
\hline$a_{11}$ & 0.3255 & $(0.1275)$ & 0.1872 & $(0.0816)$ \\
\hline$a_{21}$ & 0.1674 & $(0.0756)$ & 0.3298 & $(0.1353)$ \\
\hline$a_{21}^{*}$ & 0.2411 & $(0.0967)$ & 0.4510 & $(0.2164)$ \\
\hline$a_{22}$ & 0.2829 & $(0.1295)$ & 0.1433 & $(0.0677)$ \\
\hline$a_{31}$ & 0.3946 & $(0.0978)$ & 0.4085 & $(0.1674)$ \\
\hline$a_{31}^{*}$ & 0.2449 & $(0.0067)$ & 1.0806 & $(0.4573)$ \\
\hline$a_{33}$ & 0.1236 & $(0.0023)$ & -0.1173 & $(0.2124)$ \\
\hline LogLik & 34179.76 & & 27834.26 & \\
\hline$L B_{\text {Stock, (10) }}$ & 6.8961 & & 8.1413 & \\
\hline$L B_{\text {Stock, (10) }}^{2}$ & 9.7875 & & 10.1267 & \\
\hline
\end{tabular}

Note: see the notes to Table 2 .

of negative ones. However, since the onset of the 2008 crisis, negative news releases have become more frequent in all countries but France and Germany. The shift has been particularly marked for the PIIGS countries, that have been hit the most by the crisis. Furthermore, the average number of stories, either negative or positive, has increased substantially since 2008. This is not surprising: the Euro area has been affected deeply by the recent global crisis, and even small investors have become increasingly aware of the importance of news on the state of the economy after a decade of steadily growing stock markets that did not seem to reflect the underlying economy fundamentals. This growing interest has been captured and fuelled by a rising number of articles commenting on macro news releases. Furthermore, since 2008 there has been an increase in stock market volatility in all countries (Fig. 1). This finding supports the inclusion of a switch dummy in the model specification.

\subsection{Hypotheses tested}

We test for mean and volatility spillovers by placing restrictions on the relevant parameters; specifically we consider the following three sets of null hypotheses ${ }^{8} \mathrm{H}_{0}$ :

\section{Tests of no news spillovers to stock market returns}

$H_{01}$ :Positive news to stock markets before the 2008 crisis: $\beta_{12}=0$

$H_{02}$ :Positive news to stock markets after the 2008 crisis: $\beta_{12}^{*}=0$

$H_{03}$ :Negative news to stock markets before the 2008 crisis: $\beta_{13}=0$

\footnotetext{
${ }^{8}$ The joint restrictions $H_{05}-H_{08}$ are tested by means of a Wald test.
} 

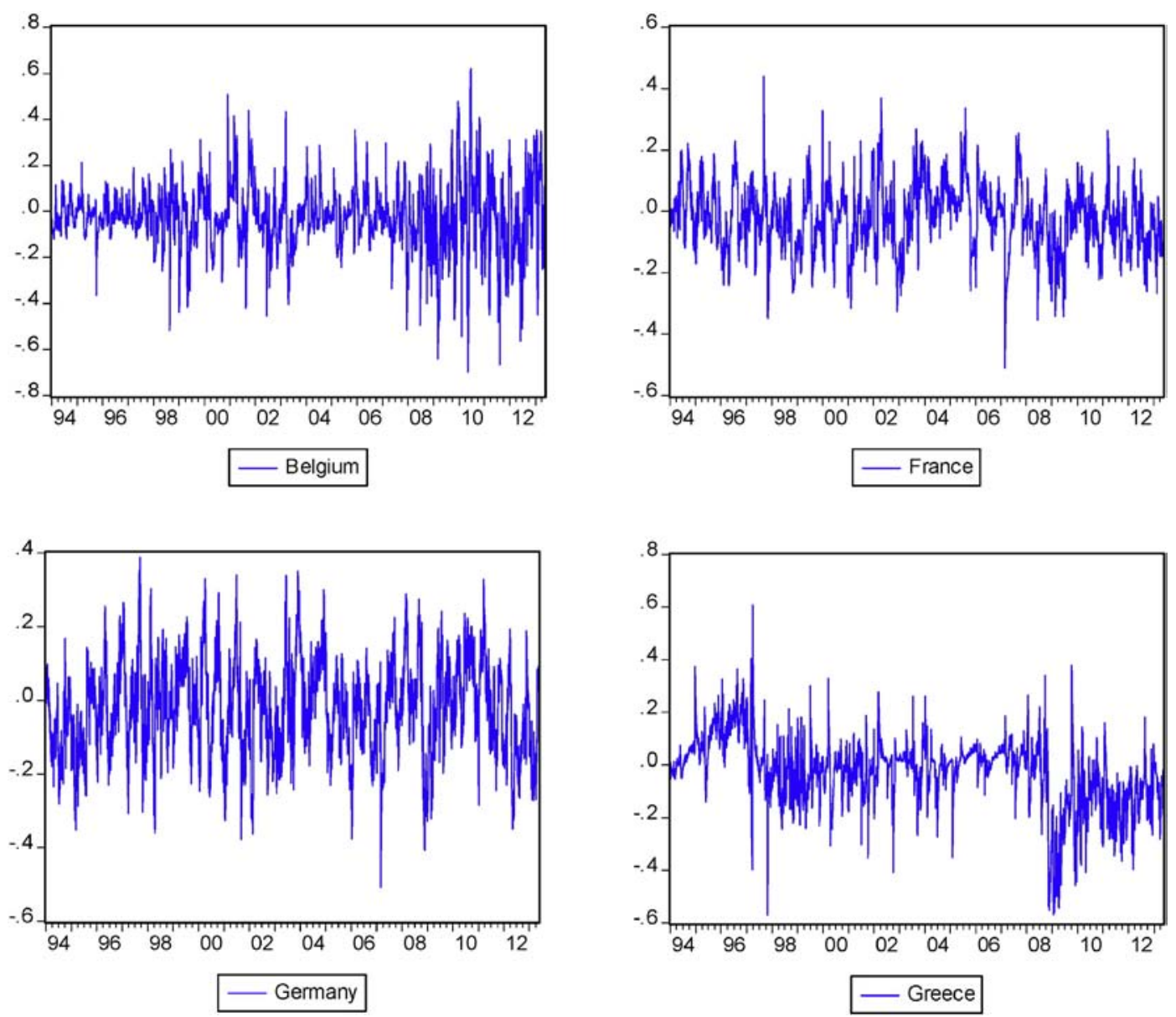

Fig. 2. Conditional correlations between negative news and stock markets returns.

$H_{04}$ :Negative news to stock markets after the 2008 crisis: $\beta_{13}^{*}=0$

2. Tests of no news volatility spillovers to stock markets volatility $H_{05}$ :Positive news volatility to stock markets before the 2008 crisis: $a_{21}=g_{21}=0$

$H_{06}$ :Positive news volatility to stock markets after the 2008 crisis: $a_{21}^{*}=g_{21}^{*}=0$

$H_{07}$ :Negative news volatility to stock markets before the 2008 crisis: $a_{31}=g_{31}=0$

$H_{08}$ :Negative news volatility to stock markets after the 2008 crisis: $a_{31}{ }^{*}=g_{31}{ }^{*}=0$

3. Tests of no news volatility spillovers to stock market returns $H_{09}$ :Positive news volatility to stock markets before the 2008 crisis: $\theta_{12}=0$

$H_{10}$ :Positive news volatility to stock markets after the 2008 crisis: $\theta_{12}^{*}=0$

$H_{11}$ :Negative news volatility to stock markets before the 2008 crisis: $\theta_{13}=0$

$H_{12}$ :Negative news volatility to stock markets after the 2008 crisis: $\theta_{13}^{*}=0$

\subsection{Discussion of the results}

In order to test the adequacy of the models, Ljung-Box portmanteau tests were performed on the standardised and squared residuals. Overall, the results indicate that the VAR-GARCH(1,1)-in-mean specification captures satisfactorily the persistence in returns and squared returns of all the series considered. Causality effects ${ }^{9}$ in the conditional mean and

\footnotetext{
9 Please note that the term causality refers to Granger causality and therefore a structural interpretation is not appropriate.
}

variance vary in magnitude and sign across countries. Note that the signs on cross-market volatilities cannot be determined. The estimated VAR-GARCH(1,1)-in-mean model with the associated robust standard errors and likelihood function values are presented in Tables 2-5. We select the optimal lag length of the mean equation using the Schwarz information criterion. The following points are noteworthy. Concerning the effects of positive news on stock market returns $\left(\beta_{12}\right)$, we find positive and significant causality at the standard $5 \%$ significance level for all eight countries. The biggest estimated coefficients are those for Ireland and Portugal, with values equal to 0.0072 and 0.0071 , respectively. The post-September 2008 results show an increase in the effect of positive news for all countries but Spain $\left(\beta_{12}+\beta_{12}{ }^{*}\left\langle\beta_{12}\right\rangle\right)$. As for the effects of negative news on stock market returns $\left(\beta_{13}\right)$, there appears to be negative and significant causality at the standard $5 \%$ significance level for all eight countries. Again the largest coefficients (in absolute value) are those for Ireland and Portugal, with values equal to -0.0134 and -0.0242 , respectively. The post-September 2008 results indicate an increase in the effects of negative news for all countries, especially in the case of the PIIGS ones, where they double in the second subsample. Overall, we find that negative news have bigger effects (in absolute value) than positive news $\left(\beta_{12}\left\langle\beta_{13}\right\rangle\right)$ in all countries considered. This pattern has been reinforced by the recent crisis.

The nature of the model allows us to control and test for the presence of reverse causation, i.e. the effects of stock market activity on the number of positive and negative news stories, measured by $\beta_{21}$ and $\beta_{31}$ respectively, but we do not find any statistically significant

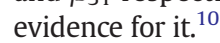

\footnotetext{
10 The results for $\beta_{21}$ and $\beta_{31}$ have not been reported to save space, but are available upon request.
} 
Concerning the conditional variance equations, the estimated "own-market" coefficients are statistically significant and the estimates of $g_{11}$ suggest a high degree of persistence. The patterns are not substantially different for the eight countries considered, with positive and negative volatility news having a significant influence on stock returns volatility (note that the sign cannot be established). The magnitude of the causality effect is bigger (in absolute value) for negative than for positive news volatility in all countries examined. Furthermore, there is evidence of the 2008 crisis affecting the causality-in-variance dynamics. In particular, the post-crisis negative news volatility effect doubled at least for the PIIGS countries, with Greece exhibiting the biggest increase $\left(a_{31}+a_{31}{ }^{*}=-0.9492\right)$ compared to the pre-September 2008 period $\left(a_{31}=-0.0873\right)$.

The news GARCH-in-mean coefficients $\left(\theta_{12}\right.$ and $\left.\theta_{13}\right)$ are negative and significant for all eight countries, showing that any increase in (positive or negative) news volatility has a negative effect on the markets. However, the magnitude of this effect is bigger when it is due to negative as opposed to positive news volatility $\left(\theta_{12}\left\langle\theta_{13}\right)\right.$ for all eight countries. The 2008 crisis seems to have played an important role, the effects of negative news volatility having more than doubled in all PIIGS countries. The investigation of such linkages is novel and suggests that news volatility, which can be interpreted as a proxy for newspapers uncertainty about the state of the economy, also influences the domestic stock markets, to an extent which varies across the different markets considered in the analysis.

Also, the exogenous variables are statistically significant for all eight countries, their estimated coefficients indicating a negative $\delta_{12}$ (TBill interest rate) and positive $\delta_{13}$ (US stock returns) effect respectively, as one would expect. These results confirm the effectiveness of the monetary policy measures implemented and their different impact on individual
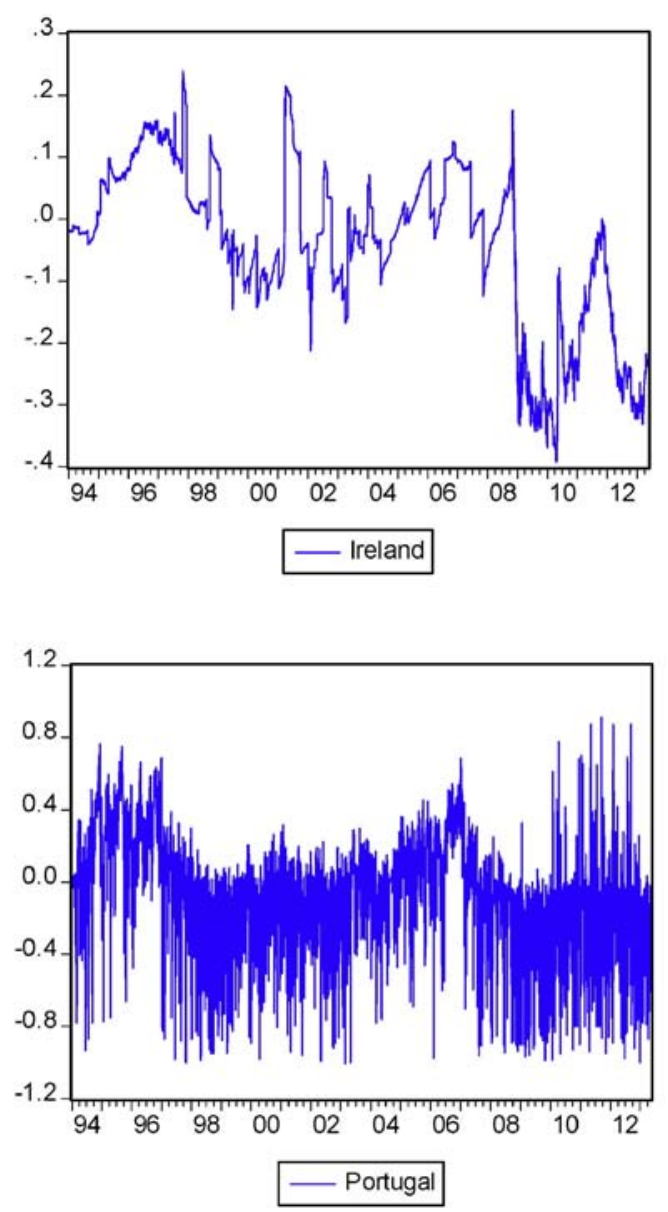

stock markets. The presence of global financial effects on domestic stock markets is also confirmed, although they are more or less pronounced depending on the country being considered.

Finally, there is also evidence of co-movement between stock market returns and the news index, as shown by the conditional correlations (Figs. 2-3) derived from the VAR-GARCH(1,1)-in-mean model. In particular, the conditional correlations between positive news and stock returns are generally positive, whereas those between negative news and stock returns are negative. The downward shift in pairwise correlations (between stock returns and negative news) is quite evident for the PIIGS countries after 2008, especially in the case of Ireland and Portugal, suggesting that financial markets in economies under pressure were particularly sensitive to negative news.

\section{Conclusions}

This paper has analysed the effects of macro news on stock returns in eight countries belonging to the Euro area (Belgium, France, Germany, Greece, Ireland, Italy, Portugal and Spain) using daily data for the period 1994-2013. As emphasised in some recent literature, investor psychology could be the explanation for the existence of a relationship between news and financial markets. Following Birz and Lott (2013), the present study uses newspaper coverage of macro news as a proxy for the way investors interpret news releases, which is a key factor determining their response. However, it makes a number of original contributions to the literature, by modelling both mean and volatility spillovers, focusing on the Euro area and the effects of the global financial crisis, and controlling for both monetary policy and global financial shocks. In particular, the econometric analysis is based on the estimation of a VAR-GARCH(1,1)-in-mean model with a BEKK representation which is
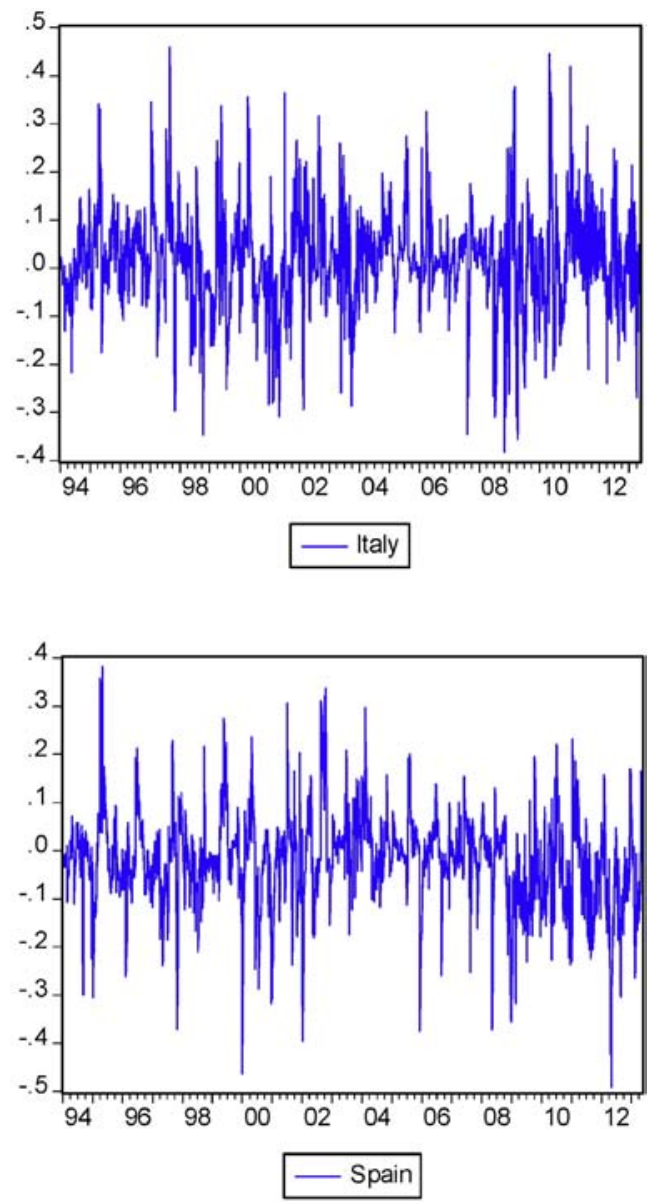

Fig. 3. Conditional correlations between negative news and stock markets returns. 
ideally suited to testing for both mean and volatility linkages between macro news and stock returns. The results can be summarised as follows. Positive (negative) news have significant positive (negative) effects on stock returns in all cases (especially in Ireland and Portugal); markets respond more to negative news, and the reaction to both types of news appears to have increased during the recent financial crisis. News volatility has a significant impact on both stock returns and their volatility, the effects being again more pronounced in the case of negative news and bigger in the most recent crisis period, especially in the PIIGS countries. Specifically, an increase in news volatility is always associated with a decrease in stock returns. The exogenous factors considered, namely the US 90-day Treasury bill rate and US stock returns, have the expected negative and positive effects respectively on stock returns. Finally, the conditional correlations between stock returns and positive (negative) news are significant and positive (negative), and their increase in absolute value in the case of negative news during the financial crisis (especially in the PIIGS countries) indicates higher sensitivity of financial markets to negative releases. Overall, our findings complement those of Birz and Lott (2013) for the US, confirming that the interpretation of macro news in the form of newspaper coverage plays a very important role in determining the response of asset prices to news releases: overlooking it might lead to underestimating the strength of the linkages between real sector news and financial markets, which appears to have increased even further since the onset of the global financial crisis, at least in the case of the Euro area examined in this study (especially in its peripheral members).

Our analysis has a number of implications for policy makers. For instance, it provides evidence that the relationship between news and asset prices is not stable over time. Our results are relevant for market participants as well: understanding linkages between news and financial variables is essential for risk and portfolio management purposes.

\section{References}

Andersen, T. G., Bollerslev, T., Diebold, F. X., \& Vega, C. (2003). Micro effects of macro announcements: Real-rime price discovery in foreign exchange. The American Economic Review, 93, 38-62.

Andersen, T. G., Bollerslev, T., Diebold, F. X., \& Vega, C. (2007). Real-time price discovery in global stock, bond and foreign exchange markets. The American Economic Review, 73, 251-277.

Antweiler, W., \& Frank, M. Z. (2004). Is all that talk just noise? The information content of Internet stock message boards. The Journal of Finance, 59, 1259-1293.

Arouri, M., Lahiani, A., \& Nguyen, D. K. (2015). World gold prices and stock returns in China: Insights for hedging and diversification strategies. Economic Modelling, 44, 273-282.

Bacchetta, P., \& van Wincoop, E. (2013). On the unstable relationship between exchange rates and macroeconomic fundamentals. Journal of International Economics, 91(1), 18-26.

Belgacem, A., Creti, A., Guesmi, K., \& Lahiani, A. (2015). Volatility spillovers and macroeconomic announcements: Evidence from crude oil markets. Applied Economics, 47(28), 2974-2984.
Birz, G., \& Lott, J. R. (2013). The effect of macroeconomic news on stock returns: New evidence from newspaper coverage. Journal of Banking E' Finance, 35, 2791-2800.

Bollerslev, T., \& Wooldridge, J. M. (1992). Quasi-maximum likelihood estimation and inference in dynamic models with time-varying covariances. Econometric Reviews, 11, $143-172$.

Boyd, J. H., Hu, J., \& Jagannathan, R. (2005). The stock market's reaction to unemployment news: Why bad news is usually good for stocks. Journal of Finance, 60, 649-670.

Campbell, J. Y., Grossman, S. J., \& Wang, J. (1993). Trading volume and serial correlation in stock returns. Quarterly Journal of Economics, 108, 905-939.

Chen, N. (1991). Financial investment opportunities and the macroeconomy. The Journal of Finance, 46, 529-554.

Coval, J. D., \& Shumway, T. (2001). Is sound just noise? The Journal of Finance, 56, 1887-1910.

Ehrmann, M., \& Fratzscher, M. (2005). Exchange rates and fundamentals: New evidence from real-time data. Journal of International Money and Finance, 24(2), 317-341.

Engelberg, J. E., \& Parsons, C. A. (2011). The causal impact of media in financial markets. The Journal of Finance, 66(1), 67-97.

Engle, R. F. (2002). Dynamic conditional correlation: A simple class of multivariate generalized autoregressive conditional heteroskedasticity models. Journal of Business $\mathcal{E}$ Economic Statistics, 20, 339-350

Engle, R. F., \& Kroner, K. F. (1995). Multivariate simultaneous generalized ARCH Econometric Theory, 11, 122-150.

Fang, L., \& Peress, J. (2009). Media coverage and the cross-section of stock returns. The Journal of Finance, 64(5), 2023-2052.

Flannery, M. J., \& Protopapadakis, A. A. (2002). Macroeconomic factors do influence aggregate stock returns. Review of Financial Studies, 15, 751-782.

Hanousek, J., Kocenda, E., \& Kutan, A. M. (2009). The reaction of asset prices to macroeconomic announcements in the new EU markets: Evidence from intraday data. Journa of Financial Stability, 5(2), 199-219.

Keynes, J. M. (1936). The general theory of employment, interest, and money. London: MacMillan.

Kocenda, E., \& Hanousek, J. (2011). Foreign news and spillovers in emerging European stock markets. Review of International Economics, 19(1), 170-188.

Ljung, G. M., \& Box, G. E. P. (1978). On a measure of lack of fit in time series models. Biometrika, 65, 297-303.

De Long, J. B., Shleifer, A., Summers, L. H., \& Waldmann, R. J. (1990). Noise trader risk in financial markets. Journal of Political Economy (98-703-738).

McQueen, G., \& Roley, V. V. (1993). Stock prices, news and business conditions. Review of Financial Studies, 92, 307-328.

Merton, R. (1973). An intertemporal capital asset pricing model. Econometrica, 41, $867-887$.

Merton, R. (1987). A simple model of capital market equilibrium with incomplete information. The Journal of Finance, 42, 483-510.

Pearce, D. K., \& Roley, V. V. (1983). The reaction of stock prices to unanticipated changes in money: A note. The Journal of Finance, 38, 1323-1333.

Pearce, D. K., \& Roley, V. V. (1985). Stock prices and economic news. Journal of Business, $58,49-67$.

Peress, J. (2011), “The impact of media in financial markets: evidence from newspaper strikes", mimeo, INSEAD, Paris.

Pericoli, M., \& Veronese, G. (2015). Forecaster heterogeneity, surprises and financial markets. WP no. 1020Rome: Bank of Italy.

Tetlock, P. C. (2007). Giving content to investor sentiment: The role of media in the stock market. The Journal of Finance, 62(3), 1139-1168.

Tetlock, P. C., Saar-Tsechansky, M., \& Macskassy, S. (2008). More than words: Quantifying language to measure firms fundamentals. Journal of Finance, 63, 1437-1467.

Wallenius, L., Fedorova, E. and M. Collan (2013), "Surprise effect of European macroeconomic announcements on CIVETS stock markets", mimeo, School of Business, Lappeenranta University of Technology, Finland. 